\title{
Política institucional do IFG: perfil do estudante de dois cursos superiores do Campus Uruaçu
}

\section{Institutional politic of IFG: student profile of higher education courses on the Campus Uruaçu}

\author{
Gilmara Barbosa de Jesus ${ }^{1}$, Yara Fonseca de Oliveira e Silva ${ }^{2}$, \\ Veronise Francisca dos Santos Lima Rebouças ${ }^{3}$, \\ Maildes Helena de Carvalho Marques ${ }^{4}$
}

\section{Resumo}

Este artigo discorre sobre a educação profissional superior tecnológica, visando identificar se o Instituto Federal de Goiás (IFG), Campus Uruaçu, no estado de Goiás, Brasil, conseguiu superar a visão assistencialista que essa modalidade de ensino vem tentando romper ao longo dos anos. Para tanto, foi levantado o perfil dos estudantes do curso de Bacharelado em Engenharia Civil (EC) e do curso de Licenciatura em Química (LQ). Visando aprofundar o entendimento sobre o assunto, formulou-se o seguinte problema: "os cursos de EC e LQ ofertados no IFG, Campus Uruaçu, têm conseguido transformar seu ensino assistencialista em uma formação que permita o desenvolvimento integral dos estudantes?". A pesquisa realizada no período de 2018 a 2019 foi de natureza aplicada e abordagem qualitativa, e, quanto aos objetivos, descritiva. Em relação aos procedimentos técnicos, foram adotadas a pesquisa bibliográfica, contemplando autores como Amaral (2017), Antunes (2009; 2018), Brzezinski (2018), Cunha (2014) e Frigotto (2007a; 2007b), e a pesquisa documental, em especial o Decreto $\mathrm{n}^{\circ} 4.127 / 1942$ e a Lei $\mathrm{n}^{\circ} 11.892 / 2008$. Foram também aplicados questionários aos 27 estudantes dos cursos pesquisados, matriculados entre os anos de 2012 e 2019, e realizadas entrevistas com 12 deles. Dentre os aspectos abordados na pesquisa, foram contemplados gênero, renda familiar, escola de origem e exercício profissional antes do ingresso no curso do IFG. Os resultados da pesquisa evidenciaram que os estudantes pesquisados têm conseguido romper com a visão assistencialista que caracteriza o ensino do IFG Campus Uruaçu.

Palavras-chave: Educação profissional; Assistencialismo institucional; Perfil do estudante.

\footnotetext{
${ }^{1}$ Mestrado em Educação, Linguagem e Tecnologias pela Universidade Estadual de Goiás (UEG), Goiânia, Goiás, Brasil. Técnica Administrativa em Educação do Instituto Federal de Goiás (IFG), Uruaçu, Goiás, Brasil. E-mail: gbarbosadejesus@gmail.com

${ }^{2}$ Doutorado em Políticas Públicas, Estratégias e Desenvolvimento pela Universidade Federal do Rio de Janeiro (UFRJ), Rio de Janeiro, Rio de Janeiro, Brasil. Pós-doutorado pela Universidade do Porto (U.Porto), Porto, Portugal. Professora da Universidade Estadual de Goiás, Goiânia, Goiás, Brasil.

${ }^{3}$ Mestrado em Educação, Linguagem e Tecnologias pela Universidade Estadual de Goiás, Goiânia, Goiás, Brasil. Servidora do Governo do Estado de Goiás na Secretaria de Estado da Educação (SEDUC), Goiânia, Goiás, Brasil. Assessora Jurídica da Procuradoria Setorial da Secretaria de Estado da Educação de Goiás, Goiânia, Goiás, Brasil.

${ }^{4}$ Mestranda em Educação na Universidade Estadual de Goiás, Goiânia, Goiás, Brasil. Professora na Secretaria de Estado de Educação, Cultura e Esporte de Goiás, Goiânia, Goiás, Brasil.
} 


\begin{abstract}
This article talks about the higher technological professional education, aiming to identify it the Federal Institute of Goiás (IFG), Campus Uruaçu, in the Goiás state, Brazil, managed to overcome the welfare view of teaching that has been trying to break through over the years. For this, was observed the profile of students in the Bachelor of Civil Engineering course and the Chemistry Graduation. Aiming to deepen the understanding about the subject, the following problem was formulated: "the courses of Civil Engineering and Chemistry Graduation offered at the IFG, Campus Uruaçu, has been managed to change its welfare teaching in a formation that allows the integral development of the students?". The research was carried out in the period of 2018 and 2019, in a qualitative approach. In relation to the technical procedures, the bibliographic research was chosen, contemplating authors as Amaral (2017), Antunes (2009; 2018), Brzezinski (2018), Cunha (2014) and Frigotto (2007a; 2007b), and the documental research, especially the Decree n. 4.127/1942 and the Law n. 11.892/2008. Questionnaires was also applied to the 27 students of the researched courses, enrolled between the years of 2012 and 2019, and conducted interviews with 12 of them. Among the aspects covered in the research, were contemplated genre, family income, school of origin and professional exercise before entering the course. The results of the research evidenced that the researched students have managed to break with the welfare vision that characterizes IFG Campus Uruaçu teaching.
\end{abstract}

Keywords: Professional education; Institutional welfare; Profile of the students.

\section{Introdução}

A política do Instituto Federal de Educação, Ciência e Tecnologia de Goiás (IFG) tem por intuito articular a educação profissional técnica e tecnológica com o mundo do trabalho (BRASIL, 2008a). Tal articulação é um desafio, pois a implementação dessa política, além disso, implica: considerar as relações da força de trabalho em uma sociedade que está organizada em grupos; romper com o assistencialismo histórico das instituições profissionalizantes; e promover a educação integral dos alunos.

É a partir dessa perspectiva que se levanta o seguinte questionamento: "tanto o curso de Bacharelado em Engenharia Civil (EC) quanto o de Licenciatura em Química (LQ) ofertados pelo IFG Campus Uruaçu têm conseguido transformar seu ensino assistencialista em uma formação que permita o desenvolvimento integral do estudante?". A resposta a essa indagação interessa a toda a sociedade goiana, em especial, à comunidade acadêmica, e para obtê-la fez-se necessário averiguar se a instituição de ensino conseguiu superar a sua visão assistencialista e promover a formação integral de seus estudantes, tal como propõe o seu Plano de
Desenvolvimento Institucional - PDI (INSTITUTO FEDERAL DE GOIÁS, 2018) e outros documentos, por exemplo, a Base da Educação Profissional (BRASIL, 2007), e a Metodologia e Relatório Consolidado de Estudos e Pesquisas com Subsídios para a Implantação dos campi do IFG de Uruaçu, Itumbiara, Luziânia, Formosa, Anápolis e da extensão do Campus Goiânia em Aparecida de Goiânia (INSTITUTO FEDERAL DE GOIÁS, 2009).

Os estudantes dos cursos pesquisados e matriculados no período compreendido entre 2012 e 2019 responderam de forma voluntária ao questionário semiestruturado, com perguntas que versaram sobre as questões de gênero, renda familiar, escola de origem, exercício profissional antes do ingresso no curso do IFG e exercício profissional na área de atuação. Para o tratamento dos dados, foram aplicadas as técnicas propostas por Gamboa (2013), que consistem em leitura exploratória, interpretação, análise crítica e registro de variáveis que possam responder ao problema levantado na pesquisa.

Os tópicos sobre a contextualização da educação profissional contemplaram os estudos de autores como Cunha (2000a), Mészáros (2005), Frigotto (2007a; 2007b), Silva (2014) e Silva e 
Romanowski (2015). Também foi realizada uma reflexão sobre a expansão da educação profissional no Brasil no período de 1980 a 2000. Os tópicos sobre o contexto da educação profissional em Goiás, com a criação e a evolução do IFG e a caracterização, criação e implantação do campus da instituição em Uruaçu, foram subsidiados pelos estudos de Antunes (2009), Brasil (2009) e Gonçalves (2014), e por documentos, tais como o Decreto $n^{\circ} 4.127 / 1942$ e a Lei $n^{0} 11.892 / 2008$ (BRASIL, 2008).

Espera-se que as análises deste artigo possam contribuir para uma compreensão maior sobre a importância do IFG Campus Uruaçu, estado de Goiás, Brasil, bem como provocar uma reflexão sobre a caracterização do estudante dessa instituição e seu papel na superação do ensino assistencialista.

\section{Contextualização da educação profissional}

A educação profissional ancora-se em um paradigma assistencialista, historicamente voltado apenas para a classe trabalhadora. Em 1909, foram criadas as Escolas de Aprendizes e Artífices, destinadas àqueles que não tinham condições de estudar e se qualificar. Mais tarde, essas escolas deram origem, em 1978, aos Centros Federais de Educação Profissional e Tecnológica (Cefet) e, em 2008, aos Institutos Federais de Educação (IFE).

O surgimento das Escolas de Aprendizes Artífices foi estabelecido pelo Decreto $\mathrm{n}^{\circ} 7.566 \mathrm{em}$ 1909, com o objetivo de atender a população desfavorecida. Esse é um marco importante na construção da rede pública de Educação Profissional no Brasil, pois define a Educação Profissional marcada pela divisão das classes sociais (SILVA; ROMANOWSKI, 2015, p. 12).

Em seu livro $O$ ensino de oficios artesanais e manufatureiros no Brasil escravocrata ${ }^{5}$, Cunha (2000a) aborda a preparação para o trabalho desde o período do Brasil Colônia até o início do século XXI. O autor afirma que a educação agrícola, mesmo sendo a base da economia em meados de 1900, não foi o que influenciou a educação profissional nem a criação da Escola de Aprendizes Artífices pelo governo do presidente Nilo Procópio Peçanha, e sim a importação de bens de capital. Esses eram considerados pelo governo como fundamentais para o aumento da produtividade e, consequentemente, da receita tributária, pois com a industrialização cresceu o número de empresas têxteis, fábricas e oficinas dos mais diversos ramos: artigos de couro, sabão, têxteis, vestuário, cerveja, fundição, vidro, dentre outros. Apesar disso, o autor pontua que a Escola de Aprendizes Artífices foi o ponto de partida para a criação de outros centros de formação, tais como o Serviço Nacional de Aprendizagem Industrial (Senai), em 1940, e as escolas técnicas da rede federal, em 1942.

Para Cunha (2000a, p. 1-2), as categorias que permitem a análise da relação entre trabalho e educação no Brasil, desde sua origem, são as seguintes: organização social do trabalho, educação, atividades produtivas e instituições. Mas no que diz respeito à história da educação no Brasil, o autor considera que "[...] os historiadores [...] se preocupam, principalmente, com o ensino que se destina às elites políticas e ao trabalho intelectual, deixando o trabalho manual em segundo plano".

Mészáros (2005) faz uma importante crítica com relação às mudanças ocorridas na educação sob certas "limitações, apriorísticas e prejulgadas", pois considera que elas não podem, de modo algum, mudar a regra geral. $\mathrm{O}$ que se tem como certo, de acordo com o autor, é que para manter a hegemonia de um determinado sistema de reprodução são admissíveis apenas as mudanças que tiverem o "[...] único e legítimo objetivo de corrigir algum detalhe defeituoso da ordem estabelecida, de forma que sejam mantidas intactas as determinações estruturais fundamentais da sociedade como um todo", mas

\footnotetext{
${ }^{5}$ Esse livro é o primeiro de uma trilogia que apresenta concepções e o desenvolvimento da história da educação profissional no Brasil. Os outros livros são $O$ ensino de oficios nos primórdios da industrialização (CUNHA, 2000b) e O ensino profissional na irradiação do industrialismo (CUNHA, 2000c).
} 
desde que estejam prioritariamente "[...] em conformidade com as exigências inalteráveis da lógica global" (MÉSZÁROS, 2005, p. 26).

$\mathrm{O}$ que se percebe são programas, projetos e reformas educacionais que devem seguir um planejamento que já está estabelecido pelo sistema e pela lógica global, modelo esse que segmenta e divide a sociedade e a coloca em um patamar linear de pensamento que podemos afirmar como descontextualizado. Em contraponto a essa política educacional e levando em consideração a educação em um mundo que não é linear, e sim contextualizado, Moraes (2003, p. 17) pontua que "[...] qualquer projeto educacional, independente da área e do nível ao qual se destina ou da clientela a ser beneficiada, requer clareza epistemológica a respeito de como ocorre o processo de construção do conhecimento e a aprendizagem".

O que se anseia é uma educação que possa romper as barreiras do neoliberalismo, implantado como projeto hegemônico no Brasil e que tem levado o sistema educacional para uma esfera mercadológica. Da mesma forma, pleiteia-se uma educação superior que tenha como objetivo a formação de sujeitos críticos, capazes de refletir sobre seu papel em sua comunidade/sociedade.

\section{Educação profissional nas décadas de 1980 e 1990}

A primeira metade da década de 1980, ainda no governo do presidente João Baptista de Oliveira Figueiredo, foi marcada por um período de recessão econômica, cujos reflexos atingiram os modos de produção e o processo educativo profissionalizante. Nesse aspecto, a reestruturação da economia brasileira foi submetida às exigências de agências e organismos internacionais, como, por exemplo, o Banco Mundial (BM), organismo que também influenciou as reformas educacionais.

Conforme Silva (2014, p. 68), para se compreender o desenvolvimento de um país, é preciso partir "[...] do princípio de que as teorias econômicas estão articuladas com os vieses social e político".
Por conseguinte, na esteira das mudanças institucionais, têm-se as reformas educativas, inclusive a profissionalizante, que passa a exigir do futuro trabalhador maior responsabilidade, flexibilidade, autonomia, competências e habilidades específicas e que contemplem a sua formação profissional para ingressar no processo produtivo.

Ainda com relação ao ensino profissionalizante, o Decreto $n^{\circ} 2.208 / 1997$, baixado durante o governo do presidente Fernando Henrique Cardoso (FHC), propôs a separação entre o ensino profissional técnico de nível médio e o ensino médio regular (BRASIL, 1997). Dessa forma, a educação profissional abarcou diferentes níveis, mas sem progressão obrigatória, ou seja, foram criados um núcleo básico - com duração variável, independente da escolaridade do estudante e sem uma regulamentação curricular - e um nível técnico, destinado aos estudantes matriculados ou egressos do ensino médio. Também foi criado o ensino tecnológico, correspondente ao nível superior, destinado aos estudantes egressos do ensino médio ou técnico.

Em atendimento ao que dispõe o Art. 214 da Constituição Federal de 1988, o governo federal formulou o Plano Nacional de Educação (PNE 2001-2010), visando à melhoria da qualidade de ensino em todos os níveis e modalidades e à redução das desigualdades sociais regionais e locais. Esse PNE valorizou a expansão dos cursos profissionalizantes em instituições privadas, mas não previu quase ou nenhum investimento na rede de ensino profissional federal (BRASIL, 1988). Nesse contexto de "[...] reestruturação produtiva, a proposta é pensar uma nova economia, um novo ensino e perspectivas políticas", conforme acentuou Silva (2014, p. 30). Para a autora, nesse cenário de reestruturação produtiva, a produtividade foi repensada e, portanto, instituições como as universidades e as empresas precisaram se adaptar para serem capazes de responder às diferentes e mutáveis demandas locais, regionais e mundiais.

Inicia-se, portanto, uma nova fase do ensino profissionalizante no País, registrando-se um aumento dos cursos nessa modalidade educacional, 
principalmente aqueles ministrados nas Escolas Técnicas Federais (Cefets), considerados de alta qualidade, e cujos egressos eram rapidamente absorvidos pelas empresas privadas e estatais. Conforme Saviani (2010), o número de matriculados nos cursos profissionalizantes aumentou consideravelmente e colocou à disposição do mercado de trabalho milhares de profissionais, até atingir a saturação decorrente do processo de recessão verificado a partir da década de 1980 .

Frigotto (2007a) esclarece que, a partir de 1993, houve importantes alterações nos objetivos dos Cefets, mas se manteve a formação de professores para os cursos profissionalizantes restrita à complementação pedagógica. $\mathrm{O}$ autor destaca ainda que somente em 1997, por meio do Decreto $\mathrm{n}^{\circ} 2.406$, é que foram ofertados cursos de licenciatura para as disciplinas científicas e tecnológicas do ensino médio e, posteriormente, com o Decreto $n^{\circ} 3.462 / 2000$, os Cefets passaram a ofertar os cursos de Licenciatura, especialmente na área de Exatas, priorizando os de Química, Matemática e Física. É possível concluir que, inicialmente, a rede federal de educação profissional tinha como objetivo formar o professor para atuar em sua própria instituição, mas na atualidade essa formação está voltada para capacitá-lo para atuar na educação básica, especialmente nas áreas de maior carência do ensino médio.

A Lei de Diretrizes e Bases da Educação Nacional - LDBEN (Lei no 9.394/1996) destinou um espaço específico para a educação profissional em relação à educação básica, com a proposta de que fosse desenvolvida em articulação com o ensino regular ou mediante diferentes estratégias em instituições especializadas ou no ambiente de trabalho (BRASIL, 1996). Sobre a educação profissional e tecnológica, a LDBEN dispõe:

Art. 39. A educação profissional e tecnológica, no cumprimento dos objetivos da educação nacional, integra-se aos diferentes níveis e modalidades de educação e às dimensões do trabalho, da ciência e da tecnologia.

$\S 1^{\circ}$ Os cursos de educação profissional e tecnológica poderão ser organizados por eixos tecnológicos, possibilitando a construção de diferentes itinerários formativos, observadas as normas do respectivo sistema e nível de ensino. $\S 2^{\circ}$ A educação profissional e tecnológica abrangerá os seguintes cursos:

I - De formação inicial e continuada ou qualificação profissional;

II - De educação profissional técnica de nível médio;

III - De Educação Profissional Superior Tecnológica de graduação e pós-graduação.

[...]

Art. 41. O conhecimento adquirido na educação profissional e tecnológica, inclusive no trabalho, poderá ser objeto de avaliação, reconhecimento e certificação para prosseguimento ou conclusão de estudos.

Art. 42. As instituições de educação profissional e tecnológica, além dos seus cursos regulares, oferecerão cursos especiais, abertos à comunidade, condicionada a matrícula à capacidade de aproveitamento e não necessariamente ao nível de escolaridade (BRASIL, 1996).

Logo depois das mudanças introduzidas no ensino profissionalizante pela LDBEN, o Decreto $n^{0} 2.208 / 1997$ modificou a estrutura da modalidade, dividindo-a nos seguintes níveis: a) básico, destinado à qualificação, requalificação e profissionalização de trabalhadores, independentemente de sua escolaridade; b) técnico, destinado à habilitação profissional para egressos do ensino médio; c) tecnológico, correspondente ao nível superior, destinado aos estudantes oriundos do ensino médio técnico (Art. $3^{\circ}$ ). Com isso, esse ramo da educação passou a integrar as diferentes formas de ensino voltadas para o trabalho, com o objetivo de atender os estudantes matriculados no nível básico, ou egressos dele, e no nível superior, além de trabalhadores em geral (BRASIL, 2007).

Frigotto (2007b) faz críticas a esse modelo de educação profissional, pois o considera como uma estrutura dualista e segmentada de ensino, dissociada da educação básica, o que provoca um aligeiramento na formação dos estudantes. Para o autor, trata-se, portanto, de uma formação superficial, principalmente para os jovens e adultos trabalhadores. 


\section{A expansão da educação profissional nos anos 2000}

O governo do presidente Luiz Inácio Lula da Silva (2003-2010), visando corrigir as distorções da educação profissional causadas pelo Decreto $\mathrm{n}^{\mathrm{o}}$ 2.208/1997, promulgou o Decreto $\mathrm{n}^{\circ}$ 5.154/ 2004, que manteve a oferta de cursos técnicos nas modalidades concomitantes e subsequentes às que foram criadas pelo decreto anterior. Trouxe, ainda, a possibilidade de integração do ensino médio à educação profissional técnica de nível médio, mas na perspectiva de uma maior expansão da modalidade, garantindo um acesso mais equitativo, em especial, de jovens e trabalhadores (BRASIL, 2004). Em seu governo, teve início o processo de expansão e interiorização da Rede Federal de Educação Profissional, Científica e Tecnológica, que culminou, em 2008, com a transformação de alguns dos Cefets em Institutos Federais de Educação, Ciência e Tecnologia (IFs).

Barbosa (2016) esclarece que a Rede Federal de Educação Profissional, Científica e Tecnológica é composta por 31 centros federais, 75 unidades descentralizadas, 39 escolas agrotécnicas, oito escolas vinculadas a universidades e sete escolas técnicas, que passaram a integrar os IFs a que compõem atualmente. De acordo com a autora, “[...] a criação dos Institutos Federais de Educação, Ciência e Tecnologia advém de uma iniciativa dos gestores da educação brasileira que visou constituir um movimento provocador de mudanças na educação profissional” (BARBOSA, 2016, p. 12). Ela esclarece ainda que os Cefets dos estados de Minas Gerais e do Rio de Janeiro não aderiram ao novo formato dos institutos federais, sob a justificativa de que ofereciam grande quantidade de cursos superiores nas áreas de graduação e pós-graduação e que o objetivo era se transformarem em universidades tecnológicas.

Outro aspecto que deve ser considerado na expansão da educação profissional é o propósito dos IFs de fomentar o desenvolvimento local e regional.
Art. $6^{\circ}$. Os Institutos Federais têm por finalidades e características:

I - ofertar educação profissional e tecnológica, em todos os seus níveis e modalidades, formando e qualificando cidadãos com vistas na atuação profissional nos diversos setores da economia, com ênfase no desenvolvimento socioeconômico local, regional e nacional;

II - desenvolver a educação profissional e tecnológica como processo educativo e investigativo de geração e adaptação de soluções técnicas e tecnológicas às demandas sociais e peculiaridades regionais;

IV - orientar sua oferta formativa em benefício da consolidação e fortalecimento dos arranjos produtivos, sociais e culturais locais, identificados com base no mapeamento das potencialidades de desenvolvimento socioeconômico e cultural no âmbito de atuação do Instituto Federal (BRASIL, 2008a).

Ao fomentarem o desenvolvimento socioeconômico local e regional, os IFs contribuiriam também para a redução das desigualdades sociais e regionais da população brasileira, conforme descreve Bacelar (2000, p. 133):

A política de desenvolvimento regional não pode deixar de ter, entre seus objetivos fundamentais, a questão da redução sistemática das desigualdades regionais que, no fundo, diz respeito ao enfrentamento das diferenças espaciais, no que se refere aos níveis de vida das populações que residem em distintas partes do território nacional e às diferentes oportunidades de emprego produtivo, a partir do qual a força de trabalho regional tenha garantida a sua subsistência.

Para que possam cumprir os objetivos de promover o desenvolvimento regional e local por meio do ensino profissional ofertado, é necessário que os IFs atendam às três dimensões estabelecidas pelo Ministério da Educação: social, geográfica e de desenvolvimento. Para Silva e Terra (2008), a dimensão social refere-se ao atendimento dos programas do governo federal cujos objetivos são os de promover o desenvolvimento econômico e universalizar programas básicos de cidadania mediante estratégias de desenvolvimento territorial 
sustentável. Em relação à dimensão geográfica, os autores explicam que se trata do atendimento prioritário às microrregiões ou aos municípios com mais de 50 mil habitantes e da interiorização da oferta pública de ensino profissionalizante. Finalmente, a dimensão de desenvolvimento preconiza que os IFs devam ser instalados em municípios preferencialmente com arranjos produtivos locais, para os quais haja investimentos que possam se caracterizar como desenvolvimento da população (SILVA; TERRA, 2008).

\section{A educação profissional em Goiás e a criação do IFG}

Estudo desenvolvido por Gonçalves (2014) mostra que até 1941 funcionava na antiga capital de Goiás, Vila Boa, a Escola de Aprendizes Artífices, precursora do Instituto Federal de Educação Profissional, Científica e Tecnológica. De acordo com a autora, com a fundação de Goiânia, a instituição foi transferida para a nova capital, e recebeu o nome de Escola Técnica de Goiânia, conforme dispunha o Decreto $n^{\circ}$ 4.127/1942. A partir de 1959, a Escola Técnica de Goiânia foi transformada em autarquia do governo federal e passou a ser denominada Escola Técnica Federal de Goiás (ETFGO).

Outra informação concedida por Gonçalves (2014) em relação à educação profissional em Goiás refere-se ao processo de discussão para a transformação da ETFGO em Cefet, iniciado em meados da década de 1990, com vistas à implantação de cursos superiores e de formação emergencial para professores da instituição. No entanto, depois de a EFTGO ser transformada em Cefet-GO, a Lei $\mathrm{n}^{\mathrm{o}}$ 11.892, de 29 de dezembro de 2008, a transformou em Instituto Federal de Educação, Ciência e Tecnologia de Goiás (IFG), e criou ainda o Instituto Federal de Educação, Ciência e Tecnologia Goiano (IF Goiano) (BRASIL, 2008a).

O IFG e o IF Goiano são instituições distintas, mas que fazem parte da Rede Federal de Educação Profissional, Científica e Tecnológica. Essa rede, conforme visto anteriormente, é uma organização política das instituições federais de educação profissional e tecnológica, também criada pela Lei $n^{0} 11.892 / 2008$, e composta pelos Institutos Federais de Educação, Ciência e Tecnologia; pelos Centros Federais de Educação Tecnológica; pelas Escolas Técnicas vinculadas às universidades federais; pela Universidade Tecnológica Federal do Paraná e pelo Colégio Pedro II, do Rio de Janeiro.

O IF Goiano agregou os antigos Cefets de Rio Verde e de Urutaí e sua respectiva unidade de ensino descentralizada de Morrinhos, mais a Escola Agrotécnica Federal de Ceres (EAFCE), todos provenientes de antigas escolas agrícolas. Atualmente, está presente em outras localidades, totalizando 12 campi. Já o IFG abarcou de início apenas duas unidades, uma de Goiânia e outra de Jataí, permanecendo assim até o ano de 2006, mas em 2016 já possuía 14 campi, distribuídos por todo o estado de Goiás.

Tanto o IFG como o IF Goiano são autarquias federais detentoras de autonomia administrativa, patrimonial, financeira, didático-pedagógica e disciplinar, equiparando-se às universidades federais. Oferecem educação superior, básica e profissional, pluricurricular e multicampi, e são especializados em educação profissional e tecnológica nas diferentes modalidades de ensino. Ambos possuem a mesma finalidade das demais instituições criadas pela Lei $n^{\circ} 11.892 / 2008$, que é a de levar educação de qualidade para jovens de todas as regiões do País. Além disso, os institutos federais têm ainda o objetivo de formar e qualificar profissionais para os diversos setores da economia, bem como realizar pesquisas e promover o desenvolvimento tecnológico de novos processos, produtos e serviços, em estreita articulação com os setores produtivos e com a sociedade, oferecendo mecanismos para a educação continuada. Tudo isso em prol da região onde se localizam seus campi, com vistas ao desenvolvimento local.

Outra finalidade dos institutos federais é a de orientar a oferta formativa em benefício da consolidação e do fortalecimento dos arranjos produtivos, sociais e culturais locais. Essas atividades são identificadas com base no mapeamento das potencialidades de desenvolvimento socioeconômico 
e cultural no âmbito de atuação de cada instituto, para promover a produção, o desenvolvimento e a transferência de tecnologias sociais, notadamente voltadas à preservação do meio ambiente (BRASIL, 2008a). Por isso, um dos objetivos dos institutos criados no estado de Goiás foi o de levar o desenvolvimento para as regiões onde foram implantadas as suas unidades. Antes da implantação de cada unidade, houve, portanto, um estudo anterior para comprovar a sua relevância para a região, o que mostra uma preocupação com sua atuação e com os impactos que podem gerar nas regiões e suas respectivas comunidades.

Em 2019, 14 unidades do IFG já haviam sido implantadas em Goiás: Goiânia, Jataí, Itumbiara, Inhumas, Uruaçu, Anápolis, Luziânia, Valparaíso, Aparecida de Goiânia, Cidade de Goiás, Senador Canedo, Goiânia Oeste, Águas Lindas e Formosa. O Campus Uruaçu do IFG, objeto desta análise, iniciou suas atividades em 25 de agosto de 2008. Localizado mais ao norte do estado, atende à demanda por educação pública e de qualidade de jovens de mais de dez municípios das mesorregiões norte e centro de Goiás.

Gonçalves (2014) destaca que, além do aumento do número de vagas proporcionado pela expansão do IFG em Goiás, a indissociabilidade entre ensino, pesquisa e extensão transformou cada uma de suas unidades em um dos estabelecimentos de ensino mais concorridos na região em que foi instalada e com a oferta de cursos de qualidade. O IFG possibilitou o acesso de diversas pessoas, tanto para fins formativos específicos para a profissionalização como também para o ingresso profissional na própria instituição, via concurso público. De qualquer maneira, concorda-se com Antunes (2009), pois a crescente demanda pela formação profissional, impulsionada pelas políticas governamentais, não se deu por acaso, e sim pela necessidade emergente de profissionalização em diversos setores econômicos com o fim de levar o País a se tornar mais competitivo no cenário mundial.

\section{Caracterização, criação e implantação do IFG Campus Uruaçu}

Para a análise da caracterização, da criação e do histórico da implantação de uma unidade do IFG no município de Uruaçu, os dados foram coletados em documentos físicos do acervo histórico no próprio campus, bem como no sítio eletrônico do instituto ${ }^{6}$. O município de Uruaçu está localizado no norte goiano, distante aproximadamente 290 quilômetros da capital do estado, Goiânia. Dados do IBGE indicam uma população aproximada de 40 mil habitantes, que, somada à dos municípios vizinhos, atinge 105.614 habitantes (IBGE, 2018).

Como Uruaçu é banhada pelo lago Serra da Mesa, por alguns anos o turismo foi o grande gerador de renda para o município, contudo, com a queda do nível da água, as atividades turísticas que proporcionava não compõem mais o seu cenário econômico. Mesmo assim, desfruta-se do valioso espaço cultural proporcionado pelo Memorial Serra da Mesa, um complexo multidisciplinar voltado para a educação ambiental, sócio-histórica e cultural.

Os primeiros estudos de viabilidade para a expansão do Cefet-GO e sua consequente instalação na cidade de Uruaçu tiveram início em 2006, quando o então diretor-geral da instituição fez uma visita ao município buscando consolidar e expandir a Rede Federal de Educação Profissional, Científica e Tecnológica.

A implantação do Cefet em Uruaçu foi autorizada pela Portaria n ${ }^{0}$ 694/2008, expedida pelo Ministério da Educação e Cultura (BRASIL, 2008b). Após reformas e adaptações no prédio doado, que possui sete pavimentos e uma área de $50 \mathrm{mil} \mathrm{m}^{2}$, o Cefet de Uruaçu foi instalado oficialmente no dia 25 de agosto de 2008, com uma aula inaugural proferida pelo então diretor-geral do Centro Federal de Educação Tecnológica de Goiás. As atividades foram iniciadas logo em seguida, com a oferta do curso superior de Licenciatura em Química, e

\footnotetext{
${ }^{6} \mathrm{https}: / / w w w . i f g . e d u . b r / u r u a c u$
} 
dos cursos técnicos em Manutenção e Suporte em Informática Integrado ao Ensino Médio (Proeja), e em Edificações, subsequente ao ensino médio. Em 2009, a instituição passou a oferecer os cursos técnicos integrados em Informática e Edificações.

Com capacidade física para atender até 1.470 estudantes, a unidade de ensino de Uruaçu ocupa atualmente uma área de 7.025,98 $\mathrm{m}^{2}$, sendo $2.800 \mathrm{~m}^{2}$ de área construída. Possui ainda uma área de terreno de $50 \mathrm{mil} \mathrm{m}^{2}$, para a qual se esperam investimentos para a construção de um complexo esportivo de padrão internacional e outras dependências administrativas e acadêmicas.

$\mathrm{Na}$ esteira de desenvolvimento dos cursos profissionais, em 2008 o Cefet-GO foi transformado em Instituto Federal de Educação, Ciência e Tecnologia de Goiás (IFG), passando a oferecer diversos cursos.

A comissão que foi formada para implantar o IFG com vários cursos, realizou levantamentos de dados e análises sobre o Município de Uruaçu e a Região de influência (compreendida em até $60 \mathrm{~km}$ a partir dele) bem como sobre alguns municípios e realidades da Região do Médio-Norte do Estado de Goiás (BRASIL, 2009, p. 14).

A metodologia de trabalho adotada pela comissão apoiou-se em três etapas, a saber: pesquisa em bancos de dados da Secretaria de Estado de Gestão e Planejamento/Superintendência de Estatísticas, Pesquisa e Informações Socioeconômicas (Seplan/Sepin) e do Instituto Brasileiro de Geografia e Estatística (IBGE); pesquisa de campo; e identificação das possíveis modalidades de atuação e de cursos a serem oferecidos pelo Campus Uruaçu (BRASIL, 2009). Em meados de dezembro de 2007, foram realizadas visitas técnicas e levantados os aspectos naturais, demográficos, econômicos e socioculturais do município de Uruaçu e de toda a região de sua influência. Apesar de a abrangência dessa região estender-se por até $60 \mathrm{~km}$, ocorreram visitas também aos municípios de Ceres, Barro Alto e Goianésia, situados fora desses limites.

O município de Goianésia, caracterizado pela diversidade de suas atividades, foi incluído como polo agroindustrial e de serviços por seu potencial de fornecedor de matérias-primas e mão de obra (INSTITUTO FEDERAL DE GOIÁS, 2009). Semelhante motivo foi utilizado para a inclusão do município de Barro Alto, cuja expansão econômica está centrada na extração e no beneficiamento do níquel e no cultivo de cana de açúcar, com projetos para a instalação de usinas de açúcar e álcool (INSTITUTO FEDERAL DE GOIÁS, 2009). Foram realizadas entrevistas com prefeitos e/ou secretários municipais, empresários e servidores públicos da educação, agentes responsáveis por tomadas de decisão nos municípios.

Esses dados fazem parte do documento publicado em 2009 "Metodologia e Relatório Consolidado de Estudos e Pesquisas com Subsídios" para a implantação dos campi de Uruaçu, Formosa, Itumbiara, Luziânia, Anápolis e da extensão do Campus Goiânia em Aparecida de Goiânia. Todas essas informações estão disponíveis no sítio da instituição ${ }^{7}$ e comprovam o estudo minucioso que precedeu a implantação não somente do campus do IFG em Uruaçu, mas também nas demais cidades.

Todo esse processo configurou-se como um eixo essencial para a tomada de decisão para a implantação do campus do IFG na cidade de Uruaçu. Influenciaram na escolha os aspectos naturais, demográficos, econômicos e socioculturais de Uruaçu; os detalhes do município e da região; as cadeias produtivas de leite, carnes e ovos; o setor de turismo e hospitalidade; o setor atacadista e o escoamento da produção; os arranjos produtivos, culturais, sociais e culturais locais/regionais; as modalidades de educação profissional e tecnológica; e os cursos profissionais, técnicos, superiores, tecnológicos e de Licenciatura em Ciências Naturais e Exatas, além da organização curricular e acadêmica sugerida.

\footnotetext{
${ }^{7}$ https://www.ifg.edu.br/
} 
Esse documento norteador foi muito importante para o processo de implantação do IFG Campus Uruaçu, uma vez que,

[...] observando as relações de trabalho e de emprego e as próprias relações sociais, percebese a influência do Município de Uruaçu em regiões vizinhas [...] temos os Municípios de Hidrolina e São Luiz do Norte, que se encontram dentro do raio estabelecido de $60 \mathrm{~km}$ do Município de Uruaçu e, ainda, os Municípios de Goianésia e de Barro Alto, que se distanciam, respectivamente, $118 \mathrm{~km}$ e $63 \mathrm{~km}$ do Município de Uruaçu (INSTITUTO FEDERAL DE GOIÁS, 2009, p. 120).

O IFG Campus Uruaçu foi planejado e implantado com o intuito de valorizar e preservar a região. $\mathrm{O}$ turismo também alavancou as possibilidades da localidade, tanto no que diz respeito às atividades econômicas como às sociais e culturais. Por isso, o instituto tem-se ancorado nessas relações com o objetivo de desenvolver a região sempre pelo viés da educação profissional de qualidade e da formação para o mundo do trabalho, o que tem relação direta com o turismo.

\section{Perfil dos sujeitos colaboradores da pesquisa}

Para compor a amostragem que fundamenta este artigo, foram escolhidos apenas os estudantes dos cursos superiores de Bacharelado em Engenharia Civil (EC) e Licenciatura em Química (LQ), sendo que 27 deles (100\%) aceitaram participar de forma voluntária, respondendo ao questionário, e 12 participaram da entrevista. Esses estudantes ingressaram nos anos de 2012, 2013, 2014 e 2015, e compõem um total de 19 estudantes do gênero feminino e oito estudantes do gênero masculino, distribuídos nos dois cursos conforme mostra o Gráfico 1.

Gráfico 1 - Gênero dos estudantes de EC e LQ do IFG Campus Uruaçu.

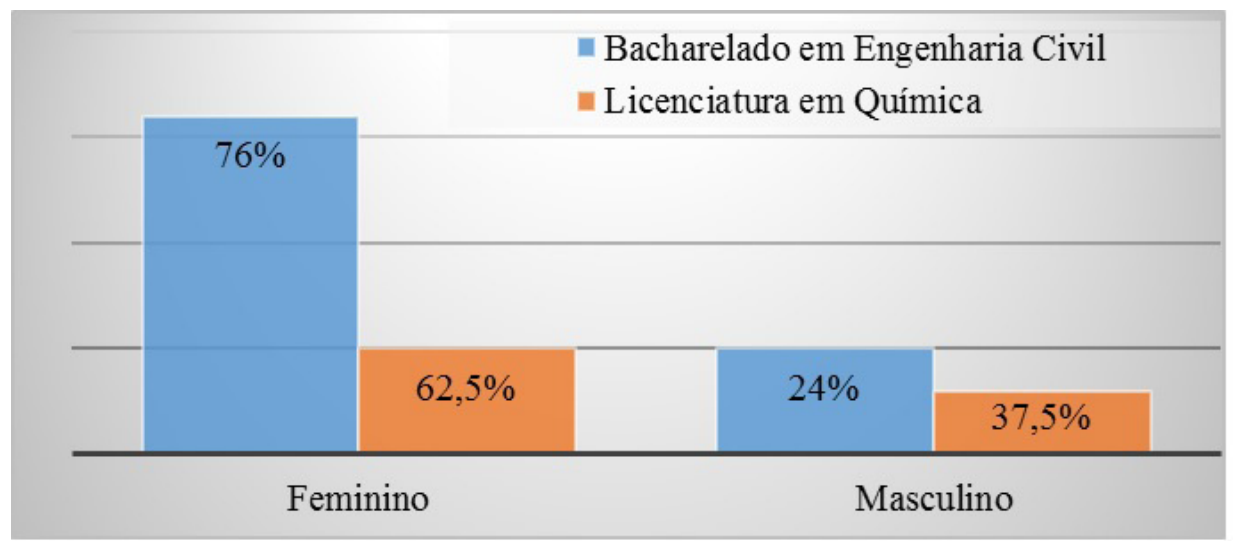

Fonte: as autoras (2021).

Para LQ, o percentual foi de $62,5 \%$ do gênero feminino e $37,5 \%$ do masculino (cinco mulheres e três homens). Para EC há uma maioria feminina significativa: $76 \%$ contra apenas $24 \%$ do gênero masculino. Percebem-se duas mudanças interessantes em relação à profissão para EC e LQ: mais mulheres estão ingressando em áreas que antes eram procuradas sobretudo pelo público masculino e mais homens estão buscando as licenciaturas, cujo público era quase que exclusivamente feminino. A respeito desse aumento de estudantes do gênero feminino, dados do Instituto Nacional de Estudos e Pesquisas Educacionais (Inep) mostraram que, em 2019, pela primeira vez o número de mulheres ultrapassou o de homens matriculados nos cursos superiores no Brasil. Em relação ao ensino tecnológico, $68 \%$ das mulheres ocuparam as vagas dos cursos, e os homens, 32\% (INSTITUTO NACIONAL DE ESTUDOS E PESQUISAS EDUCACIONAIS, 2021). 
Esse aumento da presença feminina nos cursos tecnológicos é explicado pelo avanço das mulheres no mercado de trabalho, pois a necessidade de ocupar melhores cargos e salários exigiu que se qualificassem em um curso superior. Ainda que a pesquisa indique que há um predomínio masculino, percebeu-se que no curso de Engenharia Civil houve um aumento de mulheres matriculadas. Essas informações podem ser corroboradas no Gráfico 2 a seguir.

Gráfico 2 - Gênero dos estudantes dos cursos superiores do IFG Campus Uruaçu.

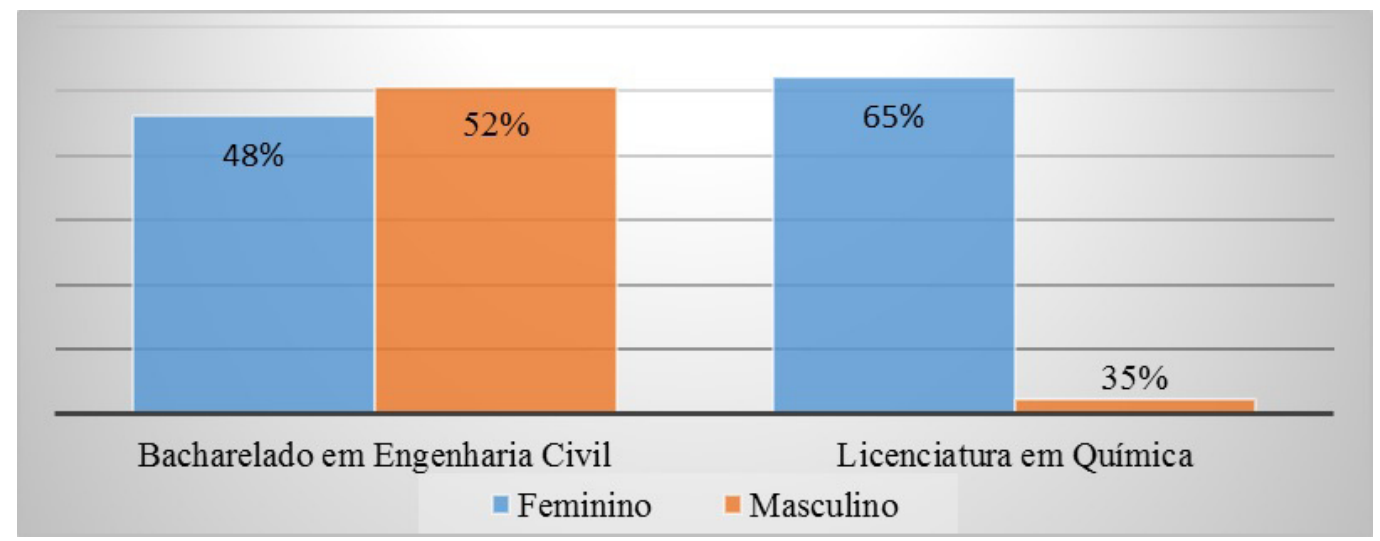

Fonte: as autoras (2021).

O campus do IFG em Uruaçu oferta os seguintes cursos: em nível superior, o de Tecnologia em Análise e Desenvolvimento de Sistemas, o Bacharelado em Engenharia Civil e a Licenciatura em Química; em nível médio, os cursos técnicos integrados em Edificações, em Informática e em Química; e na modalidade de Educação de Jovens e Adultos (EJA), o Técnico Integrado em Comércio. Apesar dessa variedade de cursos, o Gráfico 2 apresenta apenas o gênero dos estudantes dos cursos de Engenharia Civil e Licenciatura em Química, por ser esse a amostra pesquisada.

No que se refere ao gênero dos estudantes do IFG Campus de Uruaçu, os dados do Gráfico 2 mostram que havia um predomínio de homens matriculados no curso de EC, enquanto em LQ predominavam as mulheres. Em termos percentuais, esses dados mostram que, em EC, $52 \%$ dos discentes eram homens e $48 \%$, mulheres; e em LQ, 35\% eram homens e $65 \%$, mulheres. A predominância de homens no curso de EC é histórica. Estudos mais recentes conduzidos por Silva (2016) mostraram que a presença maior de homens nos cursos de EC se devia ao fato de a construção civil registrar maior número deles, enquanto a participação feminina nesse setor não acompanhou o crescimento do mercado de trabalho nos últimos anos. A pesquisa da autora identificou $97,5 \%$ da presença de homens nesse setor da engenharia, enquanto as mulheres ocupavam apenas $1,95 \%$ das funções na construção civil. Assim, apesar da predominância masculina, o Gráfico 2 mostra que o acesso da mulher a essa profissão vem crescendo.

Por outro lado, os dados do Gráfico 2 mostram um número maior de discentes do gênero feminino matriculados em LQ, evidenciando que nos cursos de Licenciatura lideram as matrículas das mulheres. A análise do gráfico também evidencia a presença diferenciada de mulheres em cursos superiores, o que mostra uma tendência expansionista desse nível de ensino nas últimas décadas e a concentração do público feminino em áreas consideradas de menor status na hierarquia das profissões. Também se infere que existe uma concentração maior de mulheres nas carreiras de magistério, inclusive em LQ, como foi apresentado acima.

Frigotto (2010b) e Antunes (2009) defendem a ideia de que essa participação das mulheres em determinadas áreas do mercado se deve à nova 
configuração do mundo do trabalho, caracterizado pela globalização. Para Frigotto (2010b), o processo de globalização ${ }^{8}$ não é um fenômeno novo, tampouco negativo, para o mercado de trabalho, pois impulsionou novos olhares e formas de perceber o capital a partir das relações sociais entre gêneros, em especial, a atuação das mulheres dentro de um contexto de emancipação no ambiente organizacional, e não apenas por uma questão de status.

Tendo por base os estudos de Antunes (2009), pôde-se confirmar o resultado da pesquisa em relação à participação das mulheres tanto no curso de EC quanto no de LQ. O autor afirma que existe um processo de bipolarização no mundo do trabalho: de um lado, as mulheres ainda são em maior número nos cursos considerados menos valorizados socialmente e que levam a funções de menor remuneração; por outro lado, a presença delas nos cursos considerados de maior status, como é o caso de EC, faz com que ocupem funções de destaque no mundo do trabalho. Mas Antunes (2009) destaca que, mesmo quando as mulheres conseguem uma posição de destaque no mercado de trabalho, seus salários são menores e ainda são discriminadas, como se não tivessem competência para assumir tal função.

O Gráfico 3, a seguir, demonstra a renda familiar dos estudantes do campus do IFG em Uruaçu, e abrange todos aqueles que estavam regularmente matriculados nos últimos períodos dos cursos superiores de EC (49) e LQ (56) em 2019, e que declararam a renda familiar no ato da matrícula. Ou seja, o número de estudantes vai além dos 27 sujeitos que aceitaram participar da pesquisa.

Gráfico 3 - Renda familiar dos estudantes do Campus Uruaçu.

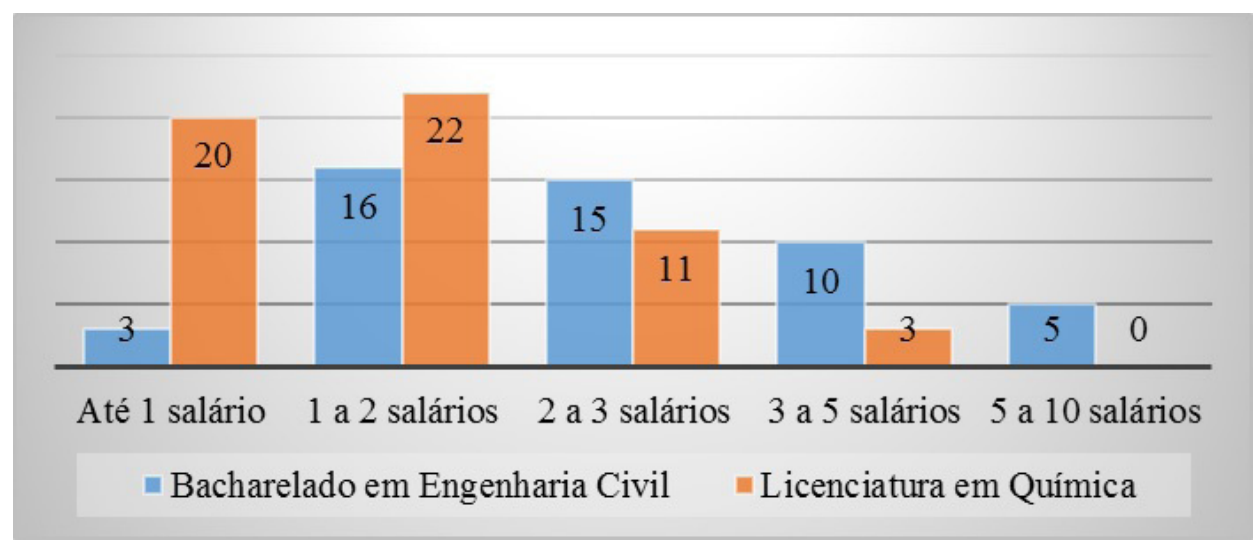

Fonte: as autoras (2021).

Os dados apresentados no Gráfico 3 mostram que a renda familiar dos estudantes do curso de EC é superior à dos alunos de LQ. Enquanto no curso de EC, em média, 30\% das famílias dos estudantes têm renda entre 3 e 10 salários mínimos, no curso de LQ mais de 95\% delas recebem somente de 1 a 3 salários mínimos mensais, o que revela uma diferença das condições econômicas dos familiares dos educandos. Essa disparidade da renda familiar dos estudantes revelou ainda que o curso de EC denota um status maior que o de LQ. Pesquisa realizada pelo Inep mostrou que quase metade das matrículas no ensino superior no Brasil se concentra em apenas dez cursos, dentre eles, o de Engenharia Civil (BRASIL, 2021).

Quando comparada a média salarial, constatase que os profissionais de EC ganham até dez vezes mais que os licenciados em Química que atuam na rede pública de ensino, denotando o status social e econômico adquirido pelos primeiros.

\footnotetext{
${ }^{8}$ Globalização é entendida neste estudo a partir de seus efeitos na revolução tecnológica e econômica mundial, o que levou a transformações no mundo do trabalho e a novas exigências aos trabalhadores, bem como para a formação desses.
} 
Constata-se que esta quarta fase do processo de globalização, iniciada no fim da década de 1980, gerou uma dificuldade para a permanência em uma profissão, processo que se inicia com o acesso à formação inicial na área de Exatas, como é o caso de Química, e aos cursos de Licenciatura destinados à formação de professores, menos valorizados e com menor status social. Essas categorias profissionais (formação, valorização remuneração e status social), em evidência neste estudo sobre o curso de LQ, estão se tornando incapazes de reverter esse ciclo de precarização.

[...] a efetiva falta de professores em algumas áreas está diretamente relacionada às condições de trabalho usualmente oferecidas; eis o problema real a ser enfrentado. Mantidas tais condições, não adianta muito ofertar oportunidades de melhoria na formação: quanto mais bem preparado se torna um professor, mais ele se afasta da sala de aula da escola básica, buscando trabalho em outros espaços (MACHADO, 2018, p. 3).

Assim, o que se apresenta é que a demanda do mundo do trabalho por uma formação constante leva os profissionais da educação a buscar oportunidades mais vantajosas financeiramente e isso provoca o abandono da docência. Esse é o caso do curso de LQ ministrado no IFG Campus Uruaçu, que possui uma grande carência exatamente de professores de Química, conforme consta em seu PPC (INSTITUTO FEDERAL DE GOIÁS, 2008), embora esse problema se estenda para a docência em todas as áreas.

Grosso modo, pode-se afirmar que alguns estudantes, em virtude do curso que escolherem, terão mais chances de virem a receber salários maiores. Esse é um fenômeno que está ligado intrinsecamente a outras questões, tais como discriminação, preconceito e mesmo desqualificação da profissão, como se o ser humano valesse pelo que faz, e não pelo que ele é, desconhecendo-se que, perante a legislação brasileira, todos os homens são iguais em seus direitos e deveres. Na prática, isso confirma o que Antunes (2009) chamou de dualização do mundo do trabalho: o trabalho para o filho do rico e o trabalho para o filho do pobre.

Conforme pontua Marx (1980, p. 43), “[...] embora declare a igualdade entre os cidadãos, o Estado mantém as estruturas da desigualdade (propriedade privada) e está comprometido em manter essa estrutura". Enquanto algumas categorias profissionais são valorizadas, a outras são impostos mecanismos de estratégia do capital, o que, diante da imprevisibilidade dos mercados, resulta em riscos acrescidos de fragmentação social, como ocorre com os estudantes de LQ.

Os dados do Gráfico 4 mostram que a maioria dos alunos do IFG, sobretudo os do curso de LQ, é oriunda da escola pública.

Gráfico 4 - Escola de origem dos estudantes dos cursos superiores do Campus Uruaçu.

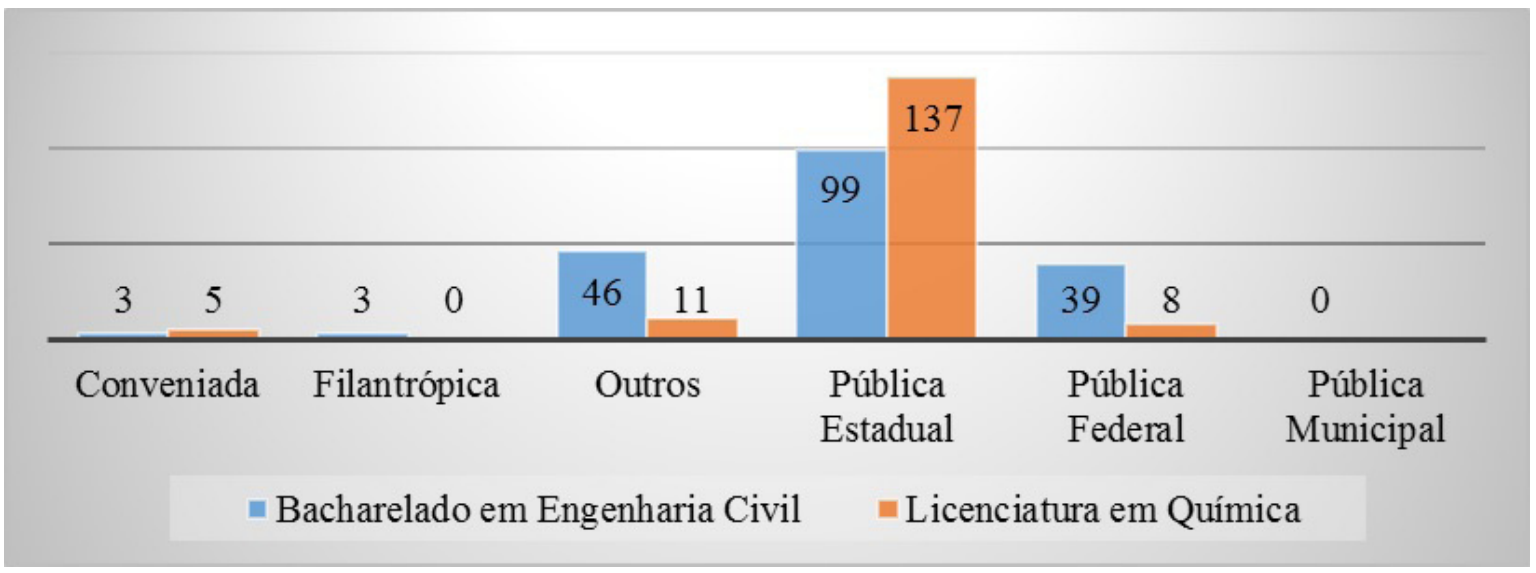

Fonte: as autoras (2021). 
No Gráfico 4 percebe-se que o acesso à educação superior da maioria dos estudantes de ambos os cursos ocorreu pela via da escola pública. Em seus estudos, Gramsci (1968) realizou um debate sobre a escola pública e seu pensamento influenciou, desde a década de 1980, a formulação de projetos em defesa da educação pública e de qualidade para todos. Frigotto (2010a) em sua obra critica a forma como a escola pública se desenvolveu no Brasil, denunciando-a como excludente e situando a instituição educacional brasileira como um dos aparelhos ideológicos do Estado capitalista, pois realiza uma função de reprodutora das relações de produção. Isso porque a escola desenvolve uma ideologia que faz os sujeitos pensarem que o sistema escolar público é universal, quando, ao contrário, ele serve para manter os interesses dos grupos dominantes.

Destaca-se, aqui, ainda que de forma incipiente, que no Brasil há um conflito entre a classe dominante, que é a detentora dos meios de produção, e a classe trabalhadora, detentora da força de trabalho. Esse conflito, ao se refletir no aparato político do Estado, conduz ao desmonte do financiamento estatal da educação, da saúde e da previdência social e à implantação de reformas que estão retirando grande parte da proteção social do trabalho e do trabalhador, mediante a flexibilização das leis trabalhistas.

Isso é decorrência das grandes corporações internacionais, transnacionais, que, de acordo com Antunes (2018, p. 155) "passou a impor à classeque-vive-do-trabalho, nos diferentes países do mundo, patamares salariais e condições de existência cada vez mais rebaixados". No caso do Brasil, isso ocorre com grande força na década de 1990, por ser um país de industrialização dependente, durante o processo de divisão do trabalho, "fundada na superexploração da força de trabalho" (ANTUNES, 2018, p. 156).

Temos então a partir daí a reestruturação produtiva no Brasil que é uma efetivação do neoliberalismo. Isso representa, segundo Antunes (2018, p. 156),
Um processo desencadeado em meio a condições de exploração particulares e articuladoras de elementos herdeiros do fordismo (ainda vigentes em vários ramos e setores produtivos) com os novos mecanismos, próprios das formas de acumulação flexível.

De modo que tem-se o processo de intensificação do trabalho para vários segmentos e que também o impõe uma reestruturação de seu trabalho de forma flexibilizada. Nesse contexto de trabalho flexível, realidade atual da classe trabalhadora, suas consequências são sentidas principalmente na própria flexibilização produtiva e além da informalidade uma "profunda precarização das condições de trabalho e vida da classe trabalhadora brasileira" (ANTUNES, 2018, p. 156).

Isso é decorrente devido à classe trabalhadora ser uma maioria expressiva nos cursos de formação, bem como nos cursos superiores, haja vista que é por meio desse nível de ensino que se poderá obter as melhores oportunidades no que diz respeito ao acesso ao emprego. Conforme nos aponta Brzezinski (2018, p. 97) acerca da estratégia de interiorização dos institutos federais que tinha como intuito a oferta de educação acolhendo aqueles que tinham interesses na educação superior pois, "vislumbrava uma perspectiva democrática de conquista de direitos constitucionais". Direitos dentre eles como acesso ao trabalho e emprego, que na atualidade só é acessível àqueles que possuem a formação na profissão desejada.

É preciso destacar que organismos internacionais, tais como o Banco Mundial (BM), o Fundo Monetário Internacional (FMI) e a Organização das Nações Unidas para a Educação, Ciência e Cultura (Unesco) foram responsáveis pelo avanço da economia de mercado, fazendo-se acreditar que a educação é a chave para o desenvolvimento humano e econômico, mas restringindo o humano ao homem produtivo e a economia ao funcionamento do mercado, conforme pontuam Almeida e Brzezinski (2020). Para os autores, no âmbito da educação profissional, a flexibilidade foi incorporada a modelos pedagógicos e conteúdos que visam tão 
somente a formação do trabalhador para o mercado de trabalho, inculcando nos indivíduos a certeza de que o mundo passa por uma transformação e que o sucesso ou fracasso econômico, social e cultural é responsabilidade deles próprios, isentando o Estado e o mercado por qualquer condição de instabilidade social e/ou econômica que os venha a acometer.

Por outro lado, Althusser (1980) defende que as políticas públicas para a educação são determinantes para o desenvolvimento de políticas afirmativas destinadas aos grupos minoritários, que, sem condições de acesso a uma escola de qualidade, puderam, mesmo na escola pública, aumentar suas chances e oportunidades para ingressar no curso superior, como visto anteriormente no Gráfico 4. Entende-se por políticas afirmativas educacionais a favor dos estudantes da escola pública as ações resultantes de suas lutas e de determinados grupos sociais e que visam o reconhecimento, a valorização e a inserção dos discentes nos programas educativos.

O desenvolvimento de políticas afirmativas que facilitam o acesso dos estudantes da escola pública ao ensino superior, neste caso comprovado com os dados mostrados no Gráfico 4, reitera o pensamento de Gramsci (1968), quando afirma que a escola única, humanista, destinada a desenvolver em cada indivíduo a sua cultura geral, tal como a educação para a vida, constitui o caminho para a democratização do ensino.

O Gráfico 5 a seguir mostra a situação profissional do estudante anterior ao seu ingresso no curso superior. Os dados são importantes por permitirem que se analise se, após o ingresso no curso, o estudante mudou sua situação profissional.

Gráfico 5 - Exercício profissional do estudante antes de ingressar no curso de EC do IFG Campus Uruaçu.

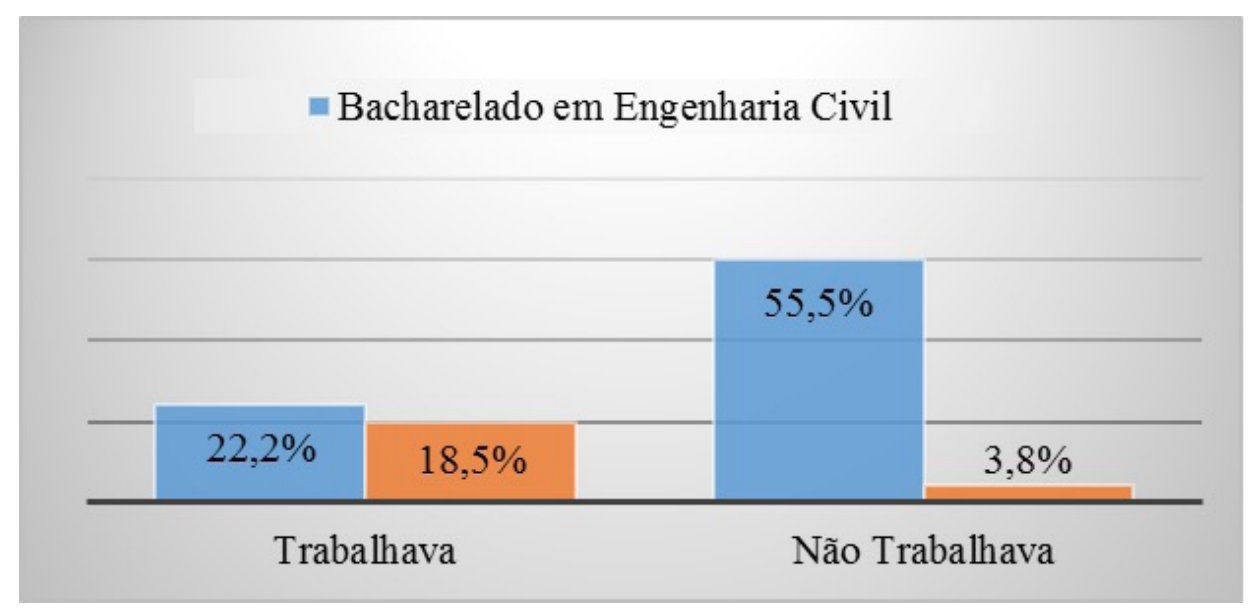

Fonte: as autoras (2021).

Dos 27 estudantes entrevistados no início do curso, 11 trabalhavam e 16, não. Depois do ingresso na educação superior, 14 estudantes responderam estar trabalhando, ou seja, três deles conseguiram trabalho. Entretanto, desses 14, apenas cinco estudantes estavam trabalhando na área do curso superior em que estavam matriculados, ou seja, 36\% trabalhavam na área e $64 \%$ em outras áreas, cujos dados são apresentados no Gráfico 6 a seguir.
Gráfico 6 - Exercício profissional na área de formação.

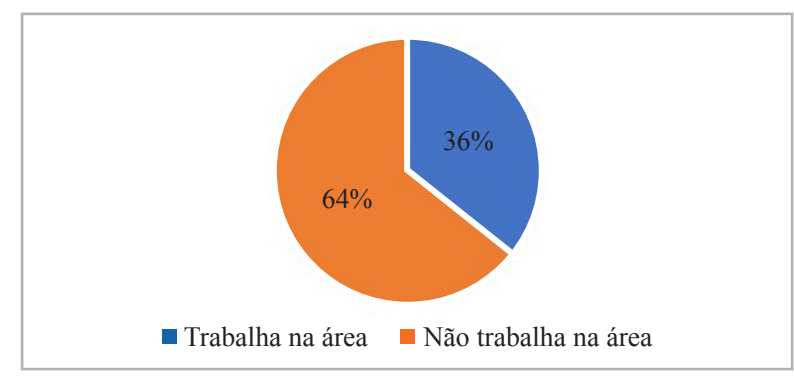

Fonte: as autoras (2021). 
A análise dos Gráficos 5 e 6 permite perceber que, apesar de haver um aumento no número de estudantes que ingressaram no mundo do trabalho depois de iniciarem o curso superior, ainda não houve uma significativa inserção na área de sua formação.

O estudo mostrou também que, apesar da predominância de homens no Bacharelado em Engenharia Civil durante o período analisado (20122019), a matrícula das mulheres nesse curso tem aumentado consideravelmente, contribuindo para uma nova perspectiva tanto sobre o próprio curso quanto ao papel que lhes é reservado para a superação de uma visão assistencialista caracterizada historicamente para a educação profissional e assim ao IFG.

Bourdieu (2008) afirma que, mesmo se todos os indivíduos tivessem acesso à escola, a organização do sistema de ensino possibilitaria a competição em seu seio, apesar da aparente igualdade de condições e possibilidades de ascensão social. Conforme o autor, os que conseguem avançar na trajetória escolar são os que conseguem destaque individual, por meio de dons, e, consequentemente, podem subir mais um degrau na hierarquia social, mas ressalta que isso não é suficiente para justificar a ascensão masculina em detrimento da feminina.

Segundo Amaral et al. (2017, p. 859), "as desigualdades entre os sexos, no que se refere à capacidade de produzir conhecimento, são construídas ao longo do tempo, sendo, primeiramente, construídas na família e na escola", por isso compreendemos o avanço da instituição ao integrar a mulher a profissões que eram acessíveis apenas aos homens, promovendo um processo de ruptura e de paradigmas.

A superação do assistencialismo tem um papel primordial para a formação integral dos estudantes, como propõe o IFG Campus Uruaçu. Por isso, ao caracterizar os estudantes dos referidos cursos neste artigo, oportunizou-se uma reflexão sobre como a instituição poderá articular ações mais efetivas para a formação profissional e tecnológica dos acadêmicos.

\section{Considerações finais}

Com objetivo de discorrer sobre a educação profissional superior tecnológica, procuramos identificar se o Instituto Federal de Goiás (IFG), Campus Uruaçu, conseguiu superar a visão histórica assistencialista impregnada nessa modalidade. Por isso, traçamos o perfil dos estudantes do curso de Bacharelado em Engenharia Civil (EC) e do curso de Licenciatura em Química (LQ), para responder ao questionamento se os cursos de EC e LQ ofertados no IFG, Campus Uruaçu, têm conseguido transformar seu ensino assistencialista em uma formação que permita o desenvolvimento integral dos estudantes.

Fez-se uso de pesquisa qualitativa para analisar documentos e realizar a caracterização dos estudantes dos cursos superiores do IFG Campus Uruaçu. Os dados da pesquisa revelaram que os estudantes dos cursos de Bacharelado em Engenharia Civil e de Licenciatura em Química do IFG, objetos do estudo, têm buscado se tornar protagonistas de seus próprios aprendizados. Esse fato os situa além da visão assistencialista que vem caracterizando o ensino ministrado pela instituição ao longo dos anos, conforme evidenciado nos Gráficos 1, 2, $3,4,5$ e 6.

Partiu-se inicialmente da contextualização da educação profissional e, por conseguinte, de um recorte histórico do contexto da criação do Campus Uruaçu, entremeado pela análise de seus documentos institucionais. Tanto no curso de Bacharelado em Engenharia Civil quanto no de Licenciatura em Química, percebeu-se uma diversidade de sujeitos de ambos os sexos, oriundos da escola pública e de contextos econômicos e educacionais distintos.

A análise dos documentos mostrou em seus fundamentos a proposta de um ensino de qualidade, baseado nos princípios da formação humana integral e integrada, da ciência, da tecnologia e da cultura como categorias indissociáveis da formação humana, bem como do trabalho e da pesquisa como parte do princípio educativo do IFG. Mas, identificou que ainda há muito a se avançar, 
sobretudo quanto ao ingresso de alunos de perfis socioeconômicos diferentes nos dois cursos analisados, o que comprova a existência de uma visão dualista de formação superior: uma para o filho do pobre e outra para o filho do rico. Os dados da renda familiar dos estudantes dos cursos de EC e LQ evidenciaram o que na prática está ocorrendo nos demais cursos da instituição e que também é percebido em outras instituições no Brasil: o curso de Bacharelado recebe alunos com situação econômica mais favorável, e o curso de Licenciatura, os estudantes menos favorecidos economicamente.

Outra questão a ser rompida diz respeito à formação destinada ao homem e à mulher, pois, como afirma Antunes $(2009$; 2018) sobre a precarização do trabalho, as profissões com baixos salários são mais acessíveis para as mulheres, o que foi percebido no Gráfico 1, que trata do gênero dos sujeitos pesquisados. Pôde-se perceber que, no curso de Química, que é de Licenciatura, predomina o público feminino, ainda que não se possa deixar de mencionar que no curso de Engenharia Civil, que é de Bacharelado, há uma certa igualdade de gênero de seu alunado, o que significa dizer que os estudantes desses cursos superiores do IFG são oriundos de diferentes classes sociais e de ambos os sexos.

$\mathrm{O}$ desenvolvimento integral que supere a visão assistencialista de ensino busca promover uma formação para além de uma lógica de mercado, que amplie horizontes de oportunidades para o mundo do trabalho, que o estudante possa ter acesso ao emprego e uma profissão, mas que também desfrute de todas as prerrogativas sociais que a profissão escolhida possa lhe oferecer: salário justo, dignidade, autonomia, identidade própria, condições laborais, respeito perante a diversidade profissional, entre outros itens que compõem a profissionalidade de uma determinada carreira. No entanto, a efetividade desse rol ainda é uma batalha vívida a ser travada.

Os avanços ocorreram, mas ainda há um longo caminho a ser percorrido até que os alunos possam de fato se tornarem protagonistas de suas próprias aprendizagens. Quanto ao IFG Campus Uruaçu, a expectativa é a de que a instituição venha a oferecer um curso menos assistencialista e tornar-se mais produtora de um saber sistematizado e igualitário.

\section{Referências}

ALMEIDA, G. C.; BRZEZINSKI, I. Unesco e a educação profissional para o século XXI: Informalidade e flexibilização como horizonte para a formação do trabalhador. Educativa, Goiânia, v. 23, p. 1-24, 2020. (Temas em Debate).

ALTHUSSER, L. Os aparelhos ideológicos do Estado. Rio de Janeiro: Graal, 1980.

AMARAL, M. A.; EMER, M. C. F. P.; BIM, S. A.; SETTI, M. G.; GONÇALVES, M. M. Investigando questões de gênero em um curso da área de computação. Revista Estudos Feministas, Florianópolis, v. 25 , n. 2, p. 857-874, maio/ago. 2017. Disponível em: https://bit.ly/3CNlrvg. Acesso em: 20 jun. 2021.

ANTUNES, R. Os sentidos do trabalho: ensaio sobre a afirmação e a negação do trabalho. São Paulo: Boitempo, 2009.

ANTUNES, R. O privilégio da servidão: o novo proletariado de serviços na era digital. São Paulo: Boitempo, 2018.

BACELAR, T. A. Ensaios sobre o desenvolvimento brasileiro: heranças e urgências. Rio de Janeiro: Revan, 2000.

BARBOSA, A. C. C. Os institutos federais: reflexões sobre a ifetização a partir do processo de elaboração do regime geral do IFS. Aracaju: IFS, 2016.

BOURDIEU, P. Para uma sociologia da ciência. Lisboa: Edições 70, 2008.

BRASIL. Constituição [1988]. Constituição da República Federativa do Brasil. Brasília, DF: Presidência da República, 1988. Disponível em: https://bit.ly/3EJkUuZ. Acesso em: 20 jun. 2019.

BRASIL. Lei no 9.394, 20 de dezembro de 1996. Estabelece as diretrizes e bases da educação nacional. Diário Oficial da União, Brasília, DF, 23 dez. 1996. Seção 1, p. 27833. 
BRASIL. Decreto $\mathrm{n}^{0}$ 2.208, de 17 de abril de 1997. Regulamenta o $\S 2^{\circ}$ do Art. 36 e os Arts. 39 a 42 da Lei no 9.394, de 20 de dezembro de 1996, que estabelece as diretrizes e bases da educação nacional. Diário Oficial da União, Brasília, DF, 1997. Seção 1, p. 7760.

BRASIL. Decreto $\mathrm{n}^{\circ} 5.154$, de 23 de julho de 2004. Regulamenta o $\S 2^{\circ}$ dos Arts. 36 a 41 da Lei $\mathrm{n}^{\circ}$ 9.394, de 20 de dezembro de 1996, que estabelece as diretrizes e bases da educação nacional e dá outras providências. Diário Oficial da União, Brasília, DF, 4 fev. 2004. Seção 1, p. 18.

BRASIL. Lei n ${ }^{\circ} 11.892$, de 29 de dezembro de 2008. Institui a Rede Federal de Educação Profissional, Ciência e Tecnológica, cria os Institutos Federais de Educação, Ciência e Tecnologia. Diário Oficial da União, Brasília, DF, 30 dez. 2008a. Seção 1, p. 1.

BRASIL. Ministério da Educação e Cultura. Documento base da educação profissional técnica de nível médio integrada ao ensino médio. Brasília, DF: Secretaria de Educação Profissional e Tecnológica, 2007.

BRASIL. Ministério da Educação e Cultura. Metodologia e relatório consolidado de estudos e pesquisas com subsídios para a implantação dos Campi de Uruaçu, Itumbiara, Luziânia, Formosa, Anápolis e da Extensão do Campus Goiânia em Aparecida de Goiânia do Instituto Federal de Goiás. Goiânia, dez. 2009. Disponível em: https:// bit.ly/3BMjNbY Acesso em: 15 jun. 2021.

BRASIL. Ministério da Educação e Cultura. Portaria $n^{0} 694$ de 9 junho de 2008. Autoriza o Centro Federal de Educação Tecnológica do Goiás CEFET-GO a promover o funcionamento de sua UNED de Uruaçu/GO. Diário Oficial da União, Brasília, DF, 10 jun. 2008b.

BRZEZINSKI, I. (org.). LDB/1996 vinte anos depois: projetos educacionais em disputa. São Paulo: Cortez, 2018.

CUNHA, L. A. O ensino de oficios artesanais e manufatureiros no Brasil escravocrata. São Paulo: Unesp; Brasília, DF: FLACSO, 2000a.

CUNHA, L. A. O ensino de ofícios nos primórdios da industrialização. São Paulo: Ed. Unesp, 2000b.
CUNHA, L. A. O Ensino profissional na irradiação do industrialismo. São Paulo: Ed. Unesp; Brasília: Flacso, 2000c. v. 3.

FRIGOTO, G. A relação da educação profissional e tecnológica com a universalização da educação básica. Educação \& Sociedade, Campinas, v. 28, n. 100, p. 1129-1152, 2007a.

FRIGOTTO, G. Educação e formação humana: ajuste neoconservador e alternativa democrática. In: GENTILI, P. A.; SILVA, T. T. (org.). Neoliberalismo, qualidade total e educação: visões. 12. ed. Petrópolis, RJ: Vozes, 2007b. p. 30-92.

FRIGOTTO, G. A produtividade da escola improdutiva: um (re) exame das relações entre educação e estrutura econômica-social capitalista. 9. ed. São Paulo: Cortez, 2010a.

FRIGOTTO, G. Educação e a crise do capitalismo real. 6. ed. São Paulo: Cortez, 2010b.

GAMBOA, S. S. Projetos de pesquisa, fundamentos lógicos: a dialética entre perguntas e respostas. Chapecó, RS: Argos, 2013.

GONÇALVES, S. L. A expansão da rede e educação profissional, científica e tecnológica: implicações nas relações e condições de trabalho no Instituto Federal de Educação, Ciência e Tecnologia de Goiás. 2014. Dissertação (Mestrado em Serviço Social) - Universidade Católica de Goiás, Goiânia, 2014.

GRAMSCI, A. Os intelectuais e a organização da cultura. Rio de Janeiro: Civilização Brasileira, 1968.

IBGE. Estimativas da População. Rio de Janeiro: IBGE, 2018. Disponível em: https://bit.ly/2ZLwQxb. Acesso em: 25 ago. 2021.

INSTITUTO FEDERAL DE GOIÁS. Portaria $n^{\circ} 488$, de 27 de agosto de 2009. Estatuto do Instituto Federal de Educação, Ciência e Tecnologia de Goiás. Goiânia: IFG, 2009. Disponível em: https:// bit.ly/3BIkzXB. Acesso em: 5 jan. 2019.

INSTITUTO FEDERAL DE GOIÁS. Projeto de Implantação do curso de Licenciatura em Química. Uruaçu: IFG, 2008. 
INSTITUTO FEDERAL DE GOIÁS. Plano de desenvolvimento institucional: 2019 a 2023. Goiânia: IFG, 2018.

INSTITUTO NACIONAL DE ESTUDOS E PESQUISAS EDUCACIONAIS - INEP. Dados estatísticos de alunos matriculados no ensino superior no Brasil. 2021. Disponível em: https://bit. ly/3bHaYFS / Acesso em: 25 ago. 2021.

MACHADO, N. J. (coord.). Diagnósticos e propostas para a educação básica brasileira. São Paulo: Instituto de Estudos Avançados da USP, São Paulo, jun. 2018. Disponível em: https://bit.ly/3CME8zt/. Acesso em: 20 jan. 2019.

MARX, K. O capital: crítica da economia política. Rio de Janeiro: Civilização Brasileira, 1980.

MÉSZÁROS, I. Educação para além do capital. São Paulo: Boitempo, 2005.

MORAES, M. C. Educar na biologia do amor e da solidariedade. Petrópolis, RJ: Vozes, 2003.

SAVIANI, D. História das ideias pedagógicas no Brasil. Campinas, SP: Autores Associados, 2010.

SILVA, A. R.; TERRA, D. C. T. A expansão dos institutos federais de educação, ciência e tecnologia e os desafios na contribuição para o desenvolvimento local e regional. In: SEMINÁRIO NACIONAL DE PLANEJAMENTO E DESENVOLVIMENTO, 1., 2008, Rio de Janeiro. Anais [...]. Rio de Janeiro: UFRJ, 2008.

SILVA, L. H. Ascensão feminina no mercado de construção civil: a percepção das gestoras. 2016. Trabalho de Conclusão de Curso (Graduação em Administração de Empresas) - Pontifícia Universidade Católica do Rio de Janeiro, Rio de Janeiro, 2016.

SILVA, M. G; ROMANOWSKI, N. A. Estudo de caso: Institutos Federais de Educação no Brasil. 2015. Dissertação (Mestrado em Educação) Universidade Metodista de São Paulo, São Paulo, 2015.

SILVA, Y. F. O. Universidade e o desenvolvimento local: o caso da Universidade Estadual de Goiás (UEG). 2014. Tese (Doutorado em Políticas Públicas, Estratégias e Desenvolvimento) - Universidade Federal do Rio de Janeiro, Rio de Janeiro, 2014.
YIN, R. K. Estudo de caso: planejamento e métodos. Tradução de Daniel Grassi. 2. ed. Porto Alegre: Bookman, 2001. 
